\title{
Synthesis of Silver (I) Coordination of Aspirinate Azo Ligands as Potential Antibacterial Agents
}

\author{
Nur Arif Mortadza1,a, Zainab Ngaini ${ }^{2, b^{*}}$, Maya Asyikin Mohamad Arif ${ }^{3, c}$ \\ ${ }^{1,2,3}$ Faculty of Resource Science and Technology, Universiti Malaysia Sarawak, \\ 94300 Kota Samarahan, Sarawak, Malaysia \\ anarifmort@gmail.com, bnzainab@unimas.my, cmamasyikin@unimas.my
}

Keywords: Aspirin; azo; silver (I); antimicrobial; turbidimetric

\begin{abstract}
The rise of antimicrobial resistance for infectious bacteria has become an alarming issue to human health. New antimicrobial drugs are in dire need and pivotal to overcome this issue. In this study, aspirinate azo ligands bearing different halogens L1-5 has been prepared via diazo-coupling reaction. The ligands L1-5 were coordinated with silver, $\mathrm{Ag}(\mathrm{I})$ metal to produce $\mathrm{Ag}(\mathrm{I})$ aspirin-azo complexes C1-5. The antibacterial properties of L1-5 and C1-5 were evaluated against Staphylococcus aureus and Escherichia coli using turbidimetric kinetic method. The complexes C15 showed comparable growth inhibition activity towards E. coli (MIC 82-105 ppm) and $S$. aureus (MIC 80-105 ppm) compared to ligands L1-5 with E. coli (MIC 83-200 ppm), S. aureus (80-131 ppm) and ampicillin (MIC 93 and 124 ppm, respectively). The excellent bacterial resistance of both L1-5 and C1-5 indicates the potential of aspirinate azo and their complexes as new antibacterial agents, which significantly benefit to the pharmaceutical industries.
\end{abstract}

\section{Introduction}

The increase of contagious bacteria has led to the emergence of drug resistance which caused many deaths in the society [1]. The development of new drugs with antimicrobial drug resistance properties is in dire need to overcome the growth of pathogenic bacteria. Several types of antimicrobial drugs have been developed through the manufacture of commercial drugs derived from azo dyes such as phenazopyridine [2].

Several studies have been reported on the synthesis of azo dyes with a wide spectrum of biological activity [3]. The azo moieties have the ability to prevent bacteria multiplication and DNA function $[4,5]$. Organic dyes featuring azo moieties $(\mathrm{N}=\mathrm{N})$ in the molecular network have also been widely studied due to their thermal and energy storage properties $[6,7,8]$.

Hybridization of azo dyes with natural product-based compounds with multifunctional groups can increase the efficiency and probability of additional interactions with biological targets/receptors [3]. Our preliminary studies on azo dyes bearing natural product-based compounds such as aspirin and kojic acid showed antibacterial activities $[3,8,9,10]$ and anticancer activity $[11,12]$.

Complexation of azo dyes with heavy metals namely $\mathrm{Ag}(\mathrm{I})$ can also increase the cytotoxic and antibacterial properties [13]. The formation of chelation between a metal ion and ligand able to improve the biological activities compared to the ligands alone [14]. Complexation is able to increase the lipophilicity of ligands, which allow the ligand to enter the bacterial cell and interact with the enzyme receptor or DNA [13]. Ag metal is well known for its antimicrobial properties [15, 16,17]. $\mathrm{Ag}$ is non-toxic to humans and has been utilized as antimicrobial agents due to its ability to interact with protein and enzyme of bacteria, which eventually leads to bacterial cell death $[18,19,20]$.

In this paper, the synthesis of natural product-based compounds namely aspirinate azo ligands L15 bearing halogens $(\mathrm{F}, \mathrm{Cl}, \mathrm{Br}, \mathrm{I})$ were synthesized via diazotization and coupling reaction. The complexes C1-5 were prepared via complexation with $\mathrm{Ag}(\mathrm{I})$ in dark condition and at room temperature. The ability of the ligands and complexes to inhibit the growth of $S$. aureus and E. coli were tested using turbidimetric kinetic method. 


\section{Experimental}

\section{Materials and instrumentational}

Chemicals and solvents were used as received from Merck. The analysis of melting point was performed using open capillary method on Stuart SMP3. Smart Omni Transmission Nicolet IS10 Perkin Elmers Thermoscientific was used to analyze FTIR spectra. ${ }^{1} \mathrm{H}$ and ${ }^{13} \mathrm{C}$ NMR spectra were obtained from JEOL ECA with ${ }^{1} \mathrm{H}$ at $500 \mathrm{MHz}$ and ${ }^{13} \mathrm{C}$ at $125 \mathrm{MHz}$ using standard reference, DMSO$\mathrm{d}_{6}$. The elemental CHNS was analyzed using Thermo-Flash (EA 1112) CHN Analyser. The transmittance values were analyzed on Optima SP-300.

\section{Synthesis of halogenated aspirin-azo ligands (L1-5)}

Sodium nitrite $(1 \mathrm{M}, 2 \mathrm{~mL})$ was poured into a solution of aniline derivatives $(5 \mathrm{mmol})$ and hydrochloric acid $(8 \mathrm{M}, 8 \mathrm{~mL})$ in an ice bath. Acetylsalicylic acid $(5 \mathrm{mmol})$ and sodium hydroxide $(1 \mathrm{M}, 10.0 \mathrm{~mL})$ were added and continue stirring for $45 \mathrm{~min}$. Hydrochloric acid $(3 \mathrm{~mL}, 8 \mathrm{M})$ was added dropwise onto the solution mixture until the precipitate formed. The solid was filtered, rinsed, recrystallized from hot ethanol and dried under vacuum to obtain the final product L1-5.

\section{Complexation of $\mathrm{Ag}$ (I) complexes [Ag(Aspirin-azo)] $\mathrm{NO}_{3}(\mathrm{C} 1-5)$}

Silver nitrate $(1 \mathrm{mmol})$ was added dropwise into aspirin-azo ligands L1-5 $(0.5 \mathrm{mmol})$ in methanol. The mixture of silver nitrate and ligand was stirred for $3 \mathrm{~h}$ in the dark at room temperature. Solid precipitates formed were filtered and washed with water followed methanol and dried to afford the final product C1-5.

\section{Antibacterial study}

Antibacterial studies of the synthesized aspirinate azo ligand L1-5 and Ag(I) complexes C1-5 were carried out against E. coli (ATCC 25922) and other common types of bacteria, S. aureus (S48/81). Both bacteria sub-cultures were grown in Luria-Bertani (LB) broth at $37^{\circ} \mathrm{C} .10 \mathrm{~mL}$ of LB broth was added with ligands and complexes at different concentrations separately (50, 80 and $100 \mathrm{ppm})$. The media and tested compounds were added with $0.2 \mathrm{~mL}$ of sub-cultured bacteria. The mixture was then stirred and incubated at $37^{\circ} \mathrm{C}$. Dimethyl sulfoxide and ampicillin were set as controls, negative and positive, respectively. The transmittance $(\mathrm{T})$ values were recorded for every $1 \mathrm{~h}(0 \mathrm{~h}-6 \mathrm{~h})$ at wavelength $560 \mathrm{~nm}$. The T values were extrapolated to colony-forming units / $\mathrm{mL}$ and articulated in $\ln \mathrm{Nt}^{2}$.

\section{Results and Discussion}

\section{Synthesis}

Aspirinate azo ligands L1-5 were initially synthesized via diazotization of halogenated anilines derivatives followed by coupling with acetylsalicylic acid with yields $24-85 \%$. Ag(I) complexes C15 were prepared satisfactorily from direct reaction of L1-5 with silver nitrate in a molar ratio of 1:2 (Ag: ligand) to produce 26-68 \% yields, where azo was acted as nitrogen chelator ${ }^{1}$. The equivalent ratio of $\mathrm{Ag}(\mathrm{I})$ and azo ligand gave similar composition and equivalent yields. The synthetic pathway of aspirinate azo ligands L1-5 and $\operatorname{Ag}(\mathrm{I})$ complexes C1-5 is shown in Scheme 1. The structural conformation of ligands L1-5 and Ag(I) complexes C1-5 was performed using CHN, FTIR and NMR spectroscopy. 
<smiles>[X]c1ccc(N)cc1</smiles>

$\mathrm{X}: 1=\mathrm{H}, 2=\mathrm{F}, 3=\mathrm{Cl}, 4=\mathrm{Br}, 5=\mathrm{I}$<smiles>[X]c1ccc(/N=N/c2ccc(O)c(C(=O)O)c2)cc1</smiles>

L1-5

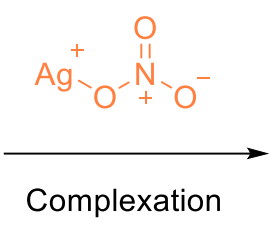<smiles>[X]c1ccc(N=[13C]([Al])O[N+](=O)[O-])cc1</smiles>

C1-5

Scheme 1. The synthetic pathway of halogenated azo-aspirin L1-5 and Ag (I) azo-aspirin complex C1-5.

Based on CHN analysis, the data obtained for L1-5 and C1-5 corresponded to the proposed structure of the ligands and complex, $\left[\mathrm{Ag}\right.$ (Aspirin-azo) $\mathrm{NO}_{3}$. The key functional group present in the IR spectra L1-5 and C1-5 is depicted in Table 1. The IR spectra of L1-5 showed a broad band in the region $1437-1487 \mathrm{~cm}^{-1}$, which attributed to the $v(\mathrm{~N}=\mathrm{N})$ [3]. The peaks presence at $1619-1688 \mathrm{~cm}^{-1}$ and $1660-1676 \mathrm{~cm}^{-1}$ were attributed to $v(\mathrm{C}=\mathrm{O})$ vibration, while the appearance of peaks at 1561$1591 \mathrm{~cm}^{-1}$ was attributed to $v($ Ar) stretching. Upon coordination of azo ligands with silver(I) ions, the FTIR peaks of C1-5 were significantly shifted indicates successful coordination to produce new silver(I) aspirinate azo compounds. All the absorption peaks attributed to $v(\mathrm{C}=\mathrm{O}), v(\mathrm{Ar})$ and $v(\mathrm{~N}=\mathrm{N})$ in C1-5 were shifted to a higher frequency [21, 22].

The significance resonance of ${ }^{1} \mathrm{H}$ and ${ }^{13} \mathrm{C}$ NMR corresponded to the $\mathbf{L 1 - 5}$ and $\mathbf{C 1 - 5}$ structure is shown in Table 2 and Table 3. The coordination of $\mathrm{Ag}(\mathrm{I})$ complex C1-5 is shown in Fig. 1.

The coordination of $\mathrm{Ag}(\mathrm{I})$ with aspirinate azo ligands L1-5 was confirmed by the shifted of peaks in the spectra. The peaks corresponded to $\mathrm{H}_{6}$ in $\mathbf{L 1 - 5}$ were assigned as a doublet at $\delta 8.30-8.33 \mathrm{ppm}$ and $\mathrm{H}_{4}$ as doublet to doublet at $\delta 7.92-8.07 \mathrm{ppm}$, which strongly indicated on the successful coupling reaction via the formation of $\mathrm{N}=\mathrm{N}$ at the para position of $\mathrm{OH}$ group. Upon coordination with $\mathrm{Ag}(\mathrm{I})$ ions, $\mathrm{H}_{4}$ was shifted to the upfield at $\delta 0.06-0.21 \mathrm{ppm}$. While $\mathrm{H}_{2}$, was shifted upfield at $\delta 0.01-$ $0.10 \mathrm{ppm}$. The shift of ${ }^{1} \mathrm{H}$ peaks was also contributed by the existence of nitrate ions $\left(\mathrm{NO}_{3}{ }^{-}\right)$in the complexes. The nitrate ions worked as a counter ion and established a small or minor interaction with an aromatic proton [23].

The ${ }^{13} \mathrm{C}$ NMR spectra of L1-5 and C1-5 were in agreement with the target structures as indicated by the occurrence of resonances at $\delta 148.5-152.2 \mathrm{ppm}$ and $\delta$ 142.7-144.4 ppm attributed to $\mathrm{C}_{1}$, and $\mathrm{C}_{5}$, respectively. Upon coordination with $\mathrm{Ag}(\mathrm{I})$ ions, $\mathrm{C}_{5}$ has shifted upfield in the range of $\delta$ 0.82$1.58 \mathrm{ppm}$. While $\mathrm{C}_{1}$, was shifted downfield in the range of $\delta 0.21-0.49 \mathrm{ppm}$ (Table 3$) . \operatorname{Ag}(\mathrm{I})$ was envisaged to coordinate with $\mathrm{N}$ bonded to $\mathrm{C}_{5}$ due to the strong shifting effect $[24,25]$.

Table 1. Summary of main FTIR band of azo ligand L1-5 and $\mathrm{Ag}(\mathrm{I})$ complex C1-5.

\begin{tabular}{|c|c|c|c|}
\hline \multirow{2}{*}{ Compound } & \multicolumn{3}{|c|}{ Wavelength $\left(\mathrm{cm}^{-1}\right)$} \\
\cline { 2 - 4 } & $v(\mathrm{C}=\mathrm{O})$ & $v(\mathrm{Ar})$ & $v(\mathrm{~N}=\mathrm{N})$ \\
\hline \hline L1 & 1688 & 1587 & 1480 \\
C1 & 1661 & 1561 & 1450 \\
\hline L2 & 1666 & 1591 & 1487 \\
C2 & 1624 & 1561 & 1444 \\
\hline L3 & 1659 & 1576 & 1478 \\
C3 & 1661 & 1580 & 1458 \\
\hline L4 & 1665 & 1574 & 1455 \\
C4 & 1619 & 1561 & 1437 \\
\hline L5 & 1661 & 1584 & 1465 \\
C5 & 1622 & 1563 & 1440 \\
\hline
\end{tabular}


Table 2. Summary of ${ }^{1} \mathrm{H}$ NMR resonances nearest to the $\mathrm{N}=\mathrm{N}$ moieties.

\begin{tabular}{|c||c|c|c|}
\hline \multirow{2}{*}{ Compound } & \multicolumn{3}{|c|}{${ }^{\mathbf{1}}$ N NR shifts in ppm } \\
\cline { 2 - 4 } & $\mathrm{H}_{4}$ & $\mathrm{H}_{6}$ & $\mathrm{H}_{2}$, \\
\hline \hline L1 & 7.920 & 8.306 & 7.840 \\
Shift value $(\mathrm{ppm})$ & 7.857 & 8.330 & 7.821 \\
\hline \hline L2 & 0.063 & 0.024 & 0.019 \\
C2 & 8.071 & 8.321 & 7.947 \\
\hline Shift value $(\mathrm{ppm})$ & 7.862 & 8.326 & 7.896 \\
\hline \hline L3 & 0.209 & 0.005 & 0.051 \\
\hline C3 & 8.077 & 8.332 & 7.880 \\
Shift value $(\mathrm{ppm})$ & 7.991 & 8.318 & 7.870 \\
\hline \hline L4 & 0.086 & 0.014 & 0.010 \\
C4 & 8.082 & 8.330 & 7.808 \\
\hline Shift value $(\mathrm{ppm})$ & 7.881 & 8.316 & 7.772 \\
\hline \hline L5 & 0.201 & 0.014 & 0.036 \\
C5 & 8.077 & 8.234 & 7.951 \\
\hline Shift value $(\mathrm{ppm})$ & 7.915 & 8.310 & 7.848 \\
\hline \hline
\end{tabular}

Table 3. The resonances of ${ }^{13} \mathrm{C}$ NMR for L1-5 and C1-5.

\begin{tabular}{|c||c|c|}
\hline \multirow{2}{*}{ Compound } & \multicolumn{2}{|c|}{${ }^{13}$ C NMR peak shifts in ppm } \\
\cline { 2 - 3 } & $\mathrm{C}_{1}{ }^{\prime}-\mathrm{N}$ & $\mathrm{C}_{5}-\mathrm{N}$ \\
\hline L1 & 151.814 & 144.460 \\
\hline Shift value $(\mathrm{ppm})$ & 152.205 & 142.895 \\
\hline \hline L2 & 0.391 & 1.385 \\
C2 & 148.580 & 144.288 \\
\hline Shift value $(\mathrm{ppm})$ & 148.914 & 142.924 \\
\hline \hline L3 & 0.334 & 1.364 \\
C3 & 150.412 & 144.298 \\
\hline Shift value $(\mathrm{ppm})$ & 150.621 & 143.477 \\
\hline \hline L4 & 0.209 & 0.821 \\
C4 & 150.707 & 144.326 \\
\hline \hline Shift value $(\mathrm{ppm})$ & 151.117 & 142.829 \\
\hline \hline L5 & 0.410 & 1.497 \\
C5 & 151.117 & 144.298 \\
\hline Shift value $(\mathrm{ppm})$ & 151.604 & 142.714 \\
\hline \hline
\end{tabular}

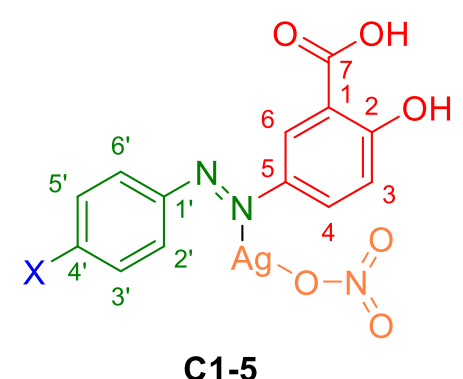

$\mathrm{X}: 1=\mathrm{H}, 2=\mathrm{F}, 3=\mathrm{Cl}, 4=\mathrm{Br}, 5=\mathrm{I}$

Figure 1. $\mathrm{Ag}(\mathrm{I})$ azo-aspirin complex C1-5 structure. 


\section{Antibacterial analysis}

Aspirinate azo ligands L1-5 and Ag(I) aspirinate azo complexes C1-5 showed antimicrobial properties screened on bacteria $S$. aureus and E. coli at the various concentration [26]. In both bacteria, MIC values were obtained by inducing the growth rate concentration to zero for both bacteria as shown in Table 4.

Table 4. MIC values of L1-5 and C1-5 for E. coli and S. aureus.

\begin{tabular}{||c||c||c|}
\hline Ligand/complex & E. coli & S. aureus \\
\hline \hline L1 & 117 & 104 \\
C1 & 82 & 104 \\
\hline L2 & $>200$ & 125 \\
C2 & 105 & 131 \\
\hline L3 & 85 & 98 \\
C3 & 91 & 80 \\
\hline L4 & 86 & 70 \\
C4 & 91 & 81 \\
\hline L5 & 83 & 80 \\
C5 & 90 & 72 \\
\hline Ampicillin & 93 & 124 \\
\hline
\end{tabular}

Ligands L1, L3-L5 demonstrated good antibacterial activities with MIC values 83-117 ppm and 70-104 ppm against $E$. coli and $S$. aureus ppm respectively, which are comparable to ampicillin (MIC $93 \mathrm{ppm}$ and $124 \mathrm{ppm}$, respectively). Aspirinate azo dyes L5 bearing iodine exhibited excellent inhibition against $E$. coli with MIC 83 ppm, while L4 bearing bromine showed excellent growth inhibition against $S$. aureus with MIC $70 \mathrm{ppm}$. The presence of azo moieties in the ligands has contributed to the strong inhibition of bacteria growth [27, 28]. Additionally, the presence of hydroxyl $(\mathrm{OH})$ and carboxyl group $(\mathrm{COOH})$ in the molecular network has contributed to the hydrophilic properties of the molecules which allowed the ligand to interact with bacteria receptors or DNA via hydrogen bonds interaction. The halogen in the ligand has contributed to the increase of antimicrobial activity. Moreover, the halogen has the capability to upsurge the lipophilicity of ligand for facile diffusion into the bacterial cell wall and membrane via the interaction of halogen bond towards bacterial receptor or DNA [29, 30, 31].

The formation of $\operatorname{Ag}(\mathrm{I})$ complexes, however, showed the increase and decrease in the antimicrobial activities (Table 4). The complexes (C1-5) gave comparable and lower MIC values of 82-105 ppm and 72-131 ppm against $E$. coli and $S$. aureus, respectively compared to ampicillin (MIC 93 ppm and 124 ppm, respectively) and the ligands L1-5. While the complexes (C1-2) demonstrated a stronger ability to inhibit the growth of E. coli with MIC $82 \mathrm{ppm}$ and $105 \mathrm{ppm}$, respectively compared to their free ligands $\mathbf{L} 1(117 \mathrm{ppm})$ and $\mathbf{L} 2(>200 \mathrm{ppm})$. While the growth inhibition activity against $S$. aureus demonstrated compound $\mathbf{C 3}$ and $\mathbf{C 5}$ with excellent MIC values of 80ppm and 72 ppm, respectively, in comparison to their ligands L3 (MIC 98 ppm) and L5 (MIC 80 ppm).

Upon coordination with Ag, the antibacterial activity was increased as the lipophilicity of the compound increased [31]. Furthermore, $\operatorname{Ag}(\mathrm{I})$ ions have also improved the $\pi$-electrons delocalization throughout the ligand molecule, thus increase its ability to penetrate the lipid cell membrane of the bacteria [32, 33]. The decrease in the inhibition activities is believed due to the high lipophilic properties of the complexes after coordinated with Ag that reduced the solubility of complexes to dissolve and react with enzyme and protein [34]. It can be concluded that the combined interaction of hydrophilicity and lipophilicity of a molecule plays an essential part in the antibacterial properties of the compounds $[3,32]$. 


\section{Conclusion}

Aspirinate azo derivatives bearing series of halogens L1-5 were successfully synthesized and coordinated with Ag to form complexes C1-5. The azo derivatives L4 gave excellent inhibition against $S$. aureus (MIC $70 \mathrm{ppm}$ ) while complex $\mathbf{C 1}$ showed excellent inhibition against $E$. coli featuring the lowest MIC value (MIC $82 \mathrm{ppm}$ ) as compared to other ligands, complexes and standard ampicillin antibiotic drug. The presence of halogens in L2-5 exhibited excellent antimicrobial activities compared to L1. Coordination of ligands with $\operatorname{Ag}(\mathrm{I})$ has increased the lipophilicity of the overall complexes and increased the antibacterial activity. C3-5 had a marginal decrease in activity for growth inhibition against $E$. coli as compared to the ligands. The excellent antibacterial properties of aspirinate azo dyes and Ag coordination have shown promising potential for the development of new antibiotic drugs in the pharmaceutical industry.

\section{Acknowledgements}

The work is financially supported through F07/FRGS/1883/2019 and Postgraduate Research Grant (F07/PGRS/1795/2019).

\section{References}

[1] M. J. Renwick, D. M. Brogan, E. Mossialos, A systematic review and critical assessment of incentive strategies for discovery and development of novel antibiotics, J. Antibiot. 69(2016):73-88.

[2] K. Bush, Why it is important to continue antibacterial drug discovery, ASM News-American Society for Microbiology. 70 (2014) 282-287.

[3] Z. Ngaini, N. A. Mortadza, Synthesis of halogenated azo-aspirin analogues from natural product derivatives as the potential antibacterial agents, Nat. Prod. Res, 33 (24) (2019) 35073514.

[4] Y. H. Khalaf, Synthesis a number of azo compounds derived from guanine and studying their biological activity on pathogenic bacteria, JUAPS. 2 (2018) 38-45.

[5] Z. Zhong, R. Xing, S. Liu, L. Wang, S. Cai, P. Li, Synthesis of acyl thiourea derivatives of chitosan and their antimicrobial activities in vitro, Carbohydr. Res. 343 (2008) 566-570.

[6] C. Z. Sie, Z. Ngaini, Incorporation of kojic acid-azo dyes on $\mathrm{TiO} 2$ thin films for dye sensitized solar cells applications, Sol Energy (2017) 1-10.

[7] C. Z. Sie, Z, Ngaini, N. Suhaili, E. Madiahlagan Synthesis of kojic ester derivatives as potential antibacterial agent, J. Chem. (2018) 1-7.

[8] E. Madiahlagan, B. N Sunil, Z. Ngaini, G. Hegde, Synthesis, liquid crystalline properties and photo switching properties of coumarin-azo bearing aliphatic chains: Application in optical storage devices, J. Mol. Liq. 292 (2019) 111328.

[9] Z. Ngaini, H. B. Kui, Synthesis and Antibacterial Activity of Azo and Aspirin-Azo Derivatives. Malaysian, J. Anal. Sci. 21 (5) (2017) 1183-1194.

[10] N. A. Nordin, T. W. Chai, B. L. Tan, C. L. Choi, A. N. Abd Halim, H. Hussain, Z. Ngaini, Novel synthetic monothiourea aspirin derivatives bearing alkylated amines as potential antimicrobial agents, J. Chem (2017) 1-7.

[11] N. A. Nordin, V.Lawai, Z. Ngaini, A. N. A. Halim, S. S. Hwang, R. E. Linton, B. K. Lee, P. M. Neilsen, In vitro cytotoxicity evaluation of thiourea derivatives bearing Salix sp. Conctituent against HK-1 cell lines. Nat. Prod. Res 34 (11) (2020) 1-11. 
[12] B. K. Ho, Z. Ngaini, P. Matthew Neilsen, S. S. Hwang, R. Entigu Linton, E. L. Kong, B. K. Lee, Synthesis and anticancer activities of 4-[(halophenyl) diazenyl] phenol and 4[(halophenyl) diazenyl] phenyl aspirinate derivatives against nasopharyngeal cancer cell lines, J. Chem (2017) 1-7.

[13] S. N. Chaulia, Metal complexes of multidentate azo dye ligand derived from 4-aminoantipyrine and 2, 4-dihydroxybenzoic acid; Synthesis, characterization and biological activity, Der Pharma Chemica. 8 (2016) 254-272.

[14] M. A. Kareem, H. D. Salman, Synthesis, Characterization and Antimicrobial Studies of TransitionMetal Complexes with Azo Ligand derivative from 4- Aminoantipyrine. Mesop Environ J (2017) 83-91.

[15] H.J. Klasen, Historical review of the use of silver in the treatment of burns. I. Early uses, Burns, 26 (2000) 117-130.

[16] J. R. Morones, J. L. Elechiguerra, A. Camacho, K. Holt, J.B. Kouri, J. T. Ramírez, M. J. Yacaman, The bactericidal effect of silver nanoparticles, Nanotechnology. 16 (2005) 2346.

[17] P. L. Drake, K. J. Hazelwood, Exposure-related health effects of silver and silver compounds: a review, Ann. Occup. Hyg. 49 (2005) 575-585.

[18] C. Greulich, D. Braun, A. Peetsch, J. Diendorf, B. Siebers, M. Epple, M. Köller, The toxic effect of silver ions and silver nanoparticles towards bacteria and human cells occurs in the same concentration range, RSC Adv. 2 (2012) 6981-6987.

[19] A. Cochis, J. Barberi, S. Ferraris, M. Miola, L. Rimondini, E. Vernè, S. Spriano, Competitive surface colonization of antibacterial and bioactive materials doped with strontium and/or silver ions, Nanomaterials. 10 (2020) 120.

[20] S. Eckhardt, P. S. Brunetto, J. Gagnon, M. Priebe, B. Giese, K. M. Fromm, Nanobio silver: its interactions with peptides and bacteria, and its uses in medicine, Chem. Rev. 113 (2013) 47084754.

[21] A. Abbas., \& R. S. Kadhim, Preparation, spectral and biological studies of azo ligand derived from proline with $\mathrm{Cu}$ (II), Ag (I) and Au (III) metal ion, J. Appl. Chem. 9 (2016) 20-31.

[22] N. J. Bello-Vieda, H. F. Pastrana, M. F. Garavito, A. G. Ávila, A. M. Celis, A. Muñoz-Castro, J. J. Hurtado, Antibacterial activities of azole complexes combined with silver nanoparticles, Molecules. 23 (2018) 361.

[23] A. Růžička, A. Lyčka, R. Jambor, P. Novák, I. Č́́sařová, M. Holčapek, M. Erben, J. Holeček Structure of azo dye organotin (IV) compounds containing a C, N-chelating ligand. Appl. Organomet. 17 (2003) 168-174.

[24] U. Kalinowska-Lis, A. Felczak, L. Chęcińska, K. Lisowska, J. Ochocki, Synthesis, characterization and antimicrobial activity of silver (I) complexes of hydroxymethyl derivatives of pyridine and benzimidazole, J. Organomet. Chem. (2014) 394-399.

[25] N. O. Al-Zamil, K. A. Al-Sadhan, A. A. Isab, M. I. Wazeer, A. R. A. Al-Arfaj, Silver (I) complexes of imidazolidine-2-thione and triphenylphosphines: Solid-state, solution NMR and antimicrobial activity studies, Spectrosc. 21 (2007) 61-67.

[26] A. N. Abd Halim, Z. Ngaini, Synthesis and bacteriostatic activities of bis (thiourea) derivatives with variable chain length, J. Chem. (2016).

[27] S. Brown, J. P. Santa Maria Jr, S. Walker, Wall teichoic acids of gram-positive bacteria, Annu. Rev. Microbiol. 67 (2013) 313-336.

[28] K. R. Raghavendra, K. A. Kumar. Synthesis of some novel azo dyes and their dyeing, redox and antifungal properties, Int. J. Chem.Tech. Res. 5 (2013) 1756-1760. 
[29] C. Bissantz, B. Kuhn, M. Stahl, A medicinal chemist's guide to molecular interactions, J. Med. Chem. 53 (2010) 5061-5084.

[30] M. Harrold, R. Zavod, Basic concepts in medicinal chemistry, ASHP, (2013).

[31] P. P. Ikokoh, H.O. Onigbanjo, O. Adedirin, J. O. Akolade, U. Amuzie, A. Fagbohun, Synthesis and Antimicrobial Activities of Copper (I) Thiourea and Silver (I) Thiourea, Open J. Res. 2 (2015) 86-91.

[32] P. Gull, A. A. Hashmi, Biological activity studies on metal complexes of macrocyclic schiff base ligand: synthesis and spectroscopic characterization, J. Braz, 26 (2015) 1331-1337.

[33] T. Aiyelabola, E. Akinkunmi, E. Obuotor, I. Olawuni, D. Isabirye, J. Jordaan, Synthesis characterization and biological activities of coordination compounds of 4-hydroxy-3-nitro-2Hchromen-2-one and its aminoethanoic acid and pyrrolidine-2-carboxylic acid mixed ligand complexes, Bioinorg. Chem. Appl. (2017).

[34] K. D. Freeman-Cook, R. L. Hoffman, T. W. Johnson, Lipophilic efficiency: the most important efficiency metric in medicinal chemistry, Future. Med. Chem. 5 (2013) 113-115. 